\title{
Correlation between polymorphism of TYMS gene and toxicity response to treatment with 5-fluoruracil and capecitabine
}

\author{
Stefano Vitello (1), Italia Di Liegro (2), Maria Rita Ricciardi (1), Chiara Verga (1), \\ Alessandra Amato (3), Gabriella Schiera (4), Carlo Di Liegro (4), Giuseppe Messina \\ (3), Patrizia Proia (3)
}

(1) Regional Hospital S. Elia, Caltanissetta, Italy; (2) Department of Experimental Biomedicine and Clinical Neurosciences (BIONEC), University of Palermo, Palermo, Italy; (3) Department of Psychological, Pedagogical and Educational Sciences, Sport and Exercise Sciences Research Unit, University of Palermo, Palermo, Italy; (4) Department of Biological Chemical and Pharmaceutical Sciences and Technologies (STEBICEF), University of Palermo, Palermo, Italy

This article is distributed under the terms of the Creative Commons Attribution Noncommercial License (CC BY-NC 4.0) which permits any noncommercial use, distribution, and reproduction in any medium, provided the original author(s) and source are credited.

\begin{abstract}
Tumorigenesis is a multiphasic process in which genetic alterations guide the progressive transformation in cancer cells 1 . In order to evaluate the possible correlation between some gene variants and the risk of the toxicity development onset, two of the polymorphisms of the thymidylate synthase (TYMS), rs34743033 (2R/3R) and rs16430 (DEL/INS) were investigated. We enrolled in our study 47 patients from the Hospital of Sicily. Our preliminary findings suggest that there could be a linkage between the genotypes discussed and the development of the toxicity following the chemotherapy treatment. These results need to be confirmed by further studies, however this short paper offers some initial insight into the relationships between genetic background and the better outcome for patients.
\end{abstract}

Key Words: Cancer, genetics, thymidylate synthase, polymorphisms, toxicity.

Eur J Transl Myol 2020; 30 (3): 8970. doi: 10.4081/ejtm.2020.8970

Cancer is a pathology characterized by dynamic alterations in the genome. ${ }^{1}$ Tumorigenesis is a multiphasic process in which the succession of genetic alterations, capable of conferring a growth advantage, guide the progressive transformation of a normal cell into a tumor cell. ${ }^{2}$ The unregulated growth of cancer cells derives from the sequential acquisition of somatic mutations and/or alterations in the expression of genes that control growth, differentiation and apoptosis; or that guarantee the integrity of the genome, i.e. those mechanisms that normally regulate cell proliferation and homeostasis. ${ }^{3}$ In recent times, numerous studies have attempted to identify predisposition factors of cancer. Genes have been identified whose reduced expression can act as biomarkers for the early diagnosis of tumors, such as Reprimo gene for gastric cancer, ${ }^{4}$ or reduced cancer incidence such as biallelic expression of EXITS genes in females explains a portion of the reduced cancer incidence compared to males across a variety of tumor types. ${ }^{5}$ The probability that an individual affected by these mutations will develop a tumor is variable and depends on various factors. These include the type of mutated allele, as well as the age and the action of other genes called modifiers. The influence of other factors such as diet, lifestyle and environmental factors remains unclear. The data obtained to date, suggests that for any type of tumor, only one or a few loci can explain the genetic risk, regardless of the type of the genetic variant (i.e., single nucleotide polymorphisms, SNPs or copynumber variations, CNVs), or frequency (wether it is common, rare or very rare). The risk of developing a tumor would instead be associated with a polygenic inheritance in which hundreds or thousands of genetic variants would be involved. A theoretical model is thus governed by a complex architecture and a multiplicity of genetic loci in which mutations in the individual genes and genetic variants present in different loci would generate tumorigenic conditions in otherwise normal tissue. This predisposing risk would then be modulated differently in each individual from environmental factors leading to tumor development. ${ }^{6}$

Timidylate Synthetase (TYMS) is an enzyme that is essential for DNA replication and repair and is also an important target for a variety of chemotherapy drugs, playing an important role not only in cancer therapy but also possibly in cancer prevention. ${ }^{7}$ Polymorphisms in the TYMS gene (rs16430) can therefore lead to altered 
enzymatic function, which can influence susceptibility to cancer. $^{7}$ Among these, a deletion/insertion of 6 base pairs has been observed at the untranslated end (3'-UTR). Therefore, there exists different genotypes related to insertion and deletion: (a) a homozygosity for deletion (Del/Del 6 bp), (b) a homozygosity for insertion (Ins/Ins $6 \mathrm{bp}$ ) or (c) a condition of heterozygosity (Del/Ins $6 \mathrm{bp}$ ). The correlation between rs 16430 and the susceptibility of many tumors including gastric cancer, colorectal cancer and breast cancer has also been highlighted in the literature, exemplifying the importance of this polymorphism in a discussion of potential cancer treatments. The risk of breast cancer has been associated with the homozygous deletion genotype, and has been more evident in older, postmenopausal women, and in those in whom menarche occurred at an older age. The homozygous insertion genotype, on the other hand, has been associated with a significantly decreased risk of breast cancer; suggestive of a protective effect given by the levels of sex hormones during the life of the subjects. The same data was subsequently confirmed in 2015 by Guan and collaborators in a case-control study carried out on non-Hispanic white women aged less than or equal to 55 years. ${ }^{8}$ The rs 16430 polymorphism of TYMS also appears to influence the susceptibility of colorectal cancer, as confirmed by Vilmos and colleagues. ${ }^{9}$ In particular, the Ins 6/Del 6 heterozygotes are less susceptible to the onset of this type of tumor. Another variant is $28 \mathrm{bp}$ variable number tandem (VNTR) polymorphism is found in 5' untraslated region (5'UTR) of TYMS, ${ }^{10}$ occuring with variable number generated two different alleles: ${ }^{11}$ two tandem repeats (2R) or three tandem repeats $(3 R)$. While $3 R$ represents the wild-type form, $2 \mathrm{R}$ represent the mutant form and the three possible genotype are: $2 \mathrm{R} / 2 \mathrm{R}, 2 \mathrm{R} / 3 \mathrm{R}$ and $3 \mathrm{R} / 3 \mathrm{R} .{ }^{12}$

5 -Fluoruracil is a chemotherapy agent that has entered the practice clinic for more than 40 years as an elective drug for the treatment of colorectal, stomach, pancreas cancers and, in some specific cases, breast cancer. ${ }^{13}$ The drug interferes with the synthesis of thymidine nucleotides, fundamental for DNA synthesis, acting on thymidylate synthetase, which is the target of chemotherapy ${ }^{14}$. Capecitabine is a non-cytotoxic fluoropyrimidine carbamate, which acts as a precursor, administered orally, of 5-Fluoruracil; is a pro-drug enzymatically converted to 5-Fluoruracil and its pathway of activation involves three enzymatic steps and two intermediate metabolites, the 5'-deoxy-5-fluorocytidine (5'-DFCR) and 5'-deoxy-5-fluorouridine (5'-DFUR) to form the 5-fluorouracil. ${ }^{15}$ After oral administration it comes absorbed quickly and extensively, it is transported in the bloodstream bound to albumin and eliminated via the kidneys. The chemotherapy toxicity is almost always the greatest limitation in choosing the appropriate therapeutic dosage that could ensure a better outcome for patients, in terms of improving both quality of life and survival. ${ }^{16}$

The aim of our study was to evaluate the possible correlation between the aforementioned gene variants and the degree of toxicity observed following chemotherapy.

\section{Materials and Methods}

\section{Patients}

We enrolled 47 patients from the Oncology Operative Unit of the Sant'Elia Hospital in Caltanissetta, Sicily. The group consisted of 24 women and 23 men aged between 39 and 85, 8 with breast cancer and 39 with gastric cancer. The aforementioned patients performed the chemotherapy treatment according to the therapeutic protocol appropriate to their pathology; particularly 17 patients in the adjuvant stage whilst the others 30 in the metastatic stage. The patients received adjuvant 5-FUbased chemotherapy mixed with a different concentration of capecitabine. Toxicity was recorded according to the criteria of the World Health Organization. Physical examination and a full blood count were performed before the chemotherapy treatment. All the patients who had received at least one course of chemotherapy were evaluated for toxicity. The same chemotherapy regimen was maintained until disease progression or severe toxicity.

\section{DNA extraction and Genotyping}

After signed informed consent from each patient, the blood sample was collected in sterile tubes containing the anticoagulant ethylenediamine tetraacetic acid (EDTA), and stored at $-90^{\circ} \mathrm{C}$ until the analysis. Genomic DNA was isolated from an aliquot of peripheral blood using a PureLink blood kit (PureLink Genomic DNA, ThermoFisher Scientific). This was used as a template for polymerase chain reaction and subsequent enzymatic

Table 1. Information on genotyping methods for each polymorphism.

\begin{tabular}{lll}
\hline GENE POLYMORPHISM & NUCLEOTIDE SEQUENCE & $\begin{array}{l}\text { ANNEALING } \\
\text { TEMPERATURE }\end{array}$ \\
AND REFERENCE ID & & $\begin{array}{l}\text { RESTRICION } \\
\text { ENZYME }\end{array}$ \\
\hline TYMS $(2 R / 3 R)$ & F-5'-GTGGCTCCTGCGTTTCCCCC - 3' & \\
rs34743033 & R-5'- GCTCCGAGCCGGCCACAGGCATGGCGCGG -3' & \\
\hline TYMS $($ DEL/INS $6 \boldsymbol{b} \boldsymbol{p})$ & F-5'-CACAAGCTATTTTTGGAAAATTT- 3' I & $56^{\circ}$ \\
rs16430 & R-5'- GACGAATGCAGAACACTTCT- 3' & \\
\hline
\end{tabular}


Table 2. Crosstab: Hematological -toxicity*Independent variables

\begin{tabular}{|c|c|c|c|c|}
\hline $\begin{array}{l}\text { Independent } \\
\text { Variable }\end{array}$ & Level & $\begin{array}{l}\text { Toxicity } \\
\text { (subjects number) }\end{array}$ & $\begin{array}{l}\text { No- Toxicity } \\
\text { (subjects number) }\end{array}$ & Total \\
\hline \multirow[t]{2}{*}{ Gender } & Male & 13 & 10 & 23 \\
\hline & Female & 16 & 8 & 24 \\
\hline \multicolumn{2}{|l|}{ Total } & 29 & 18 & 47 \\
\hline \multirow[t]{3}{*}{ Genotype 1} & $2 \mathrm{R} / 2 \mathrm{R}$ & 5 & 0 & 5 \\
\hline & $2 \mathrm{R} / 3 \mathrm{R}$ & 14 & 10 & 24 \\
\hline & $3 \mathrm{R} / 3 \mathrm{R}$ & 10 & 8 & 18 \\
\hline \multicolumn{2}{|l|}{ Total } & 29 & 18 & 47 \\
\hline \multirow[t]{3}{*}{ Genotype 2} & Ins/Ins & 7 & 8 & 15 \\
\hline & Del/Ins & 13 & 7 & 20 \\
\hline & Del/Del & 9 & 3 & 12 \\
\hline \multicolumn{2}{|l|}{ Total } & 29 & 18 & 47 \\
\hline \multirow[t]{2}{*}{ Tumor type } & Gastric & 23 & 16 & 39 \\
\hline & Breast & 6 & 2 & 8 \\
\hline \multicolumn{2}{|l|}{ Total } & 29 & 18 & 47 \\
\hline \multirow[t]{2}{*}{ Tumor stage } & Adjuvant & 9 & 8 & 17 \\
\hline & Metastatic & 20 & 10 & 30 \\
\hline \multicolumn{2}{|l|}{ Total } & 29 & 18 & 47 \\
\hline
\end{tabular}

digestion when request, to detect the genotype of TYMS gene variants (Table 1).

Statistical analysis

In order to evaluate the association between dependent variables (gastric and hematological toxicity) and independent variables (genotype 1, genotype 2, tumor stage, tumor type, gender). The distribution frequencies of independent variable parameters, for all subjects were calculated. Dichotomic variables were expressed as number and percentage and analyzed with the Fisher's exact probability test. The chi-square test was possible perform only between the dependent variable

Table 3. Crosstab: Gastric-toxicity*Independent variables

\begin{tabular}{|c|c|c|c|c|}
\hline Independent Variable & Level & $\begin{array}{l}\text { Toxicity } \\
\text { (subjects number) }\end{array}$ & $\begin{array}{l}\text { No- Toxicity } \\
\text { (subjects number) }\end{array}$ & Total \\
\hline \multirow[t]{2}{*}{ Gender } & Male & 2 & 21 & 23 \\
\hline & Female & 6 & 18 & 24 \\
\hline \multicolumn{2}{|l|}{ Total } & 8 & 39 & 47 \\
\hline \multirow[t]{3}{*}{ Genotype 1} & $2 \mathrm{R} / 2 \mathrm{R}$ & 0 & 5 & 5 \\
\hline & $2 \mathrm{R} / 3 \mathrm{R}$ & 5 & 19 & 24 \\
\hline & $3 \mathrm{R} / 3 \mathrm{R}$ & 3 & 15 & 18 \\
\hline \multicolumn{2}{|l|}{ Total } & 8 & 39 & 47 \\
\hline \multirow[t]{3}{*}{ Genotype 2} & Ins/Ins & 1 & 14 & 15 \\
\hline & Del/Ins & 4 & 16 & 20 \\
\hline & Del/Del & 3 & 9 & 12 \\
\hline \multicolumn{2}{|l|}{ Total } & 8 & 39 & 47 \\
\hline \multirow[t]{2}{*}{ Tumor type } & Gastric & 7 & 32 & 39 \\
\hline & Breast & 1 & 7 & 8 \\
\hline \multicolumn{2}{|l|}{ Total } & 8 & 39 & 47 \\
\hline \multirow[t]{2}{*}{ Tumor stage } & Adjuvant & 1 & 16 & 17 \\
\hline & Metastatic & 7 & 23 & 30 \\
\hline \multicolumn{2}{|l|}{ Total } & 8 & 39 & 47 \\
\hline
\end{tabular}




\begin{tabular}{l} 
Table 4.Univariate analysis: statistical data of Fisher's test and chi-square test, ( $p<0.05$ is significant). \\
\begin{tabular}{|l|l|l|l|l|}
\hline Independent variables & \multicolumn{1}{|c|}{ Hematological toxicity } & \multicolumn{2}{c|}{ Gastric toxicity } \\
\hline & $\begin{array}{l}\text { Fisher's Exact Test } \\
\text { value }\end{array}$ & $\begin{array}{l}\text { Exact Significant } \\
\text { value (p-value) }\end{array}$ & $\begin{array}{l}\text { Fisher's Exact } \\
\text { Test value }\end{array}$ & $\begin{array}{l}\text { Exact } \\
\text { value (p-value) }\end{array}$ \\
\hline Gender & $.512^{*}$ & $.556^{*}$ & 2.303 & .245 \\
\hline Genotype 1 & 3.33 & .225 & .820 & .862 \\
\hline Genotype 2 & 2,33 & .325 & 1.86 & .380 \\
\hline Tumor type & .758 & .692 & .149 & 1 \\
\hline Tumor stage & 2.06 & .334 & 2.45 & .361 \\
\hline
\end{tabular} \\
\hline
\end{tabular}

hematological toxicity and the independent variable gender. Results were expressed as p-value. Significance was defined as value of $\mathrm{p}$ (alpha error) $<0.05$. The analyzes were performed using IBM SPSS Statistics 23.0 (IBM SPSS Inc., Chicago, IL).

\section{Results and Discussion}

From the entire treatment sample $61.70 \%$ shown hematological toxicity, while only $17,02 \%$ shown gastric toxicity. The remaining patients didn't develop any toxicity. Descriptive analyses for each variable are shown in Table 2 and Table 3. The univariate analysis didn't show any statistically significant effect between hematological toxicity after treatment and independent variable: gender $\mathrm{p}>.05$ chi-square .512 , genotype 1 $(2 \mathrm{R} / 3 \mathrm{R}) \mathrm{p}>.05$, genotype 2 (Del/Ins) p>.05, tumor type (gastric or breast) $\mathrm{p}>.05$, tumor stage $\mathrm{p}>.05$. As to gastric toxicity, the univariate analysis didn't show any statistically significant effect between treatment and the independent variable: gender $\mathrm{p}>.05$, genotype $1(2 \mathrm{R} / 3 \mathrm{R})$ $\mathrm{p}>.05$, genotype 2 (Del/Ins) p>.05, tumor type (gastric or breast) $p>.05$, tumor stage $p>.05$ (Table 4$)$. The treatment of the different cancer with these two effective drugs often collides with their toxic. This factor represents the greatest limitation in choosing appropriate therapeutic dosage that could ensure a better outcome for the patients. During the past fifty years the use of 5Fluoruracil, a chemotherapy agent that belongs to the family of antimetabolites and, specifically, it is an analogue of pyrimidines continued to improve. The drug interferes with the synthesis of thymidine nucleotides, fundamental for DNA synthesis, acting on thymidylate synthetase, which becomed the target of chemotherapy. ${ }^{14}$ Capecitabine is a non-cytotoxic fluoropyrimidine carbamate, which acts as a precursor to 5-Fluoruracil. In this present study, we investigated whether the analysis of two common polymorphisms of the TYMS gene in gastric and breast cancer patients who received 5-FUbased chemotherapy mixed with Capecitabine, could be used to predict the toxicity to the chemotherapy treatment. We investigated 47 patients who were treated at the Sant'Elia Hospital, Caltanissetta Sicily.

In genotypes distribution, the most frequent genotype for the TYMS gene polymorphism rs16430 was the heterozygous Del/Ins (42.5\%) while the rarest one was
Del/Del genotype (25.5\%). With regards to the polymorphism rs34743033, there was a high incidence of the $2 \mathrm{R} / 3 \mathrm{R}$ genotype $(51 \%)$ and a low presence of the $2 \mathrm{R} / 2 \mathrm{R}$ genotype $(10.6 \%)$. No statistically significant correlation between the genotypes and the development of the toxicity was detected but particular attention must be paid to genotype 1 where all the 5 subjects with $2 \mathrm{R} / 2 \mathrm{R}$ genotype showed hematological toxicity, but not gastric toxicity development after treatment. These preliminary results need further investigations analyzing a wider variety of polymorphisms on control subjects and on a larger cohort of patients.

\section{List of acronyms}

CNVs - copy-number variations,

EXITS - Escape from X-Inactivation Tumor Suppressor SNPs - single nucleotide polymorphisms

TYMS - thymidylate synthase

VNTR - variable number tandem

3'-UTR - untranslated end

5'-DFCR - 5'-deoxy-5-fluorocytidine

5'-DFUR -5'-deoxy-5-fluorouridine

5'-UTR - untraslated end

\section{Authors contributions}

IDL, SV, PP made substantial contributions to conception and design. RRR and CV contributed to acquisition of data. AA performed statistical analysis and interpretation of data. CMDL and GS drafted the article with the help of GM. PP revised the article critically for important intellectual content. All authors approved the final version and agreed to be accountable for all aspects of the work in ensuring that questions related to the accuracy and integrity of any part of the work are appropriately investigated and resolved.

\section{Acknowledgments}

The authors would like to thanks all the patients involved in the study and the healthcare professionals that cooperated with us.

\section{Funding None}

\section{Conflict of Interest}

The authors declare they have no financial, personal, or other conflicts of interest. 


\section{Ethical Publication Statement}

We confirm that we have read the Journal's position on issues involved in ethical publication and affirm that this report is consistent with those guidelines.

\section{Corresponding Author}

Giuseppe Messina, Department of Psychological, Pedagogical and Educational Sciences, Sport and Exercise Sciences Research Unit, University of Palermo, Palermo I-90128, Italy.

ORCID iD: 0000-0003-2774-4950

Email: giuseppe.messina17@unipa.it

\section{Emails and ORCID iD of Coauthors}

Stefano Vitello: stefano_vitello@teletu.it

ItaliaDi Liegro: italia.diliegro@unipa.it

ORCID iD: 0000-0002-0546-1274

Maria Rita Ricciardi: mariaritaricciardi88@gmail.com Chiara Verga: chiaraverga@hotmail.it. Alessandra Amato: alessandra.amato02@unipa.it ORCID iD: 0000-0002-6512-3840

Gabriella Schiera: gabriella.schiera@unipa.it. ORCID iD: 0000-0002-8638-6455

Carlo di Liegro: carlomaria.diliegro@unipa.it. ORCID iD: 0000-0001-7362-7814.

Patrizia Proia: patrizia.proia@unipa.it ORCID iD: 0000-0002-0326-5560

\section{References}

1. Pradeepkiran JA, Sainath SB, Kumar KK, et al. CGMD: An Integrated Database of Cancer Genes and Markers. Sci Rep 2015;5:12035. doi: 10.1038 /srep12035.

2. Ebadi MR, Aghdam MK, Lima ZS, Younesi L. Investigation into breast cancer and partial breast reconstruction: A review. Eur J Transl Myol 2019;29(2):8157. doi: 10.4081/ejtm.2019.8157

3. Bloomfield M, Duesberg P. Inherent variability of cancer-specific aneuploidy generates metastases. Mol Cytogenet. 2016;9:90. doi:10.1186/s13039016-0297-x

4. Abbasi A, Heydari S. Studying the expression rate and methylation of Reprimo gene in the blood of patients suffering from gastric cancer. Eur J Transl Myol 2018;28(2):7423. doi: 10.4081/ejtm.2018. 7423.

5. Dunford A, Weinstock DM, Savova V, et al. Tumor-suppressor genes that escape from Xinactivation contribute to cancer sex bias. Nat Genet 2017;49(1):10-16. doi:10.1038/ng.3726

6. Galvan A, Ioannidis JP, Dragani TA. Beyond genome-wide association studies: genetic heterogeneity and individual predisposition to cancer. Trends Genet 2010;26:132-41. doi: 10.1016/j.tig.2009.12.008
7. Ulrich CM, Bigler J, Velicer CM, et al. Searching expressed sequence tag databases: discovery and confirmation of a common polymorphism in the thymidylate synthase gene. Cancer Epidemiol Biomarkers Prev 2000;91381-5.

8. Guan X, Liu H, Ju J, et al. Genetic Variant rs16430 $6 \mathrm{bp}>0 \mathrm{bp}$ at the microRNA-Binding Site in TYMS and Risk of Sporadic Breast Cancer Risk in NonHispanic White Women Aged $\leq 55$ Years. Mol Carcinog 2015;54:281-90. doi: 10.1002/mc.22097. Epub 2013 Oct 26.

9. Vilmos A, Hitre E, Köves I, et al. Heterozygote deficiency in thymidylate synthase enhancer region polymorphism genotype distribution in Hungarian colorectal cancer patients. Int J Cancer 2005;108: 852-6.

10. Wang X, Wang Y, Wang Y, et al. Association of thymidylate synthase gene 3'-untranslated region polymorphism with sensitivity of non-small cell lung cancer to pemetrexed treatment: TS gene polymorphism and pemetrexed sensitivity in NSCLC. Journal of biomedical science, 2013;20:5. Doi 10.1186/1423-0127-20-5

11. Mo A, Zhao Y, Shi Y, et al. Association between polymorphisms of thymidylate synthase gene 5'and 3'-UTR and gastric cancer risk: meta-analysis. Biosci rep 2016;36, e00429. org/10.1042/BSR 20160273

12. Fu Z, Jiao Y, Li Y, et al. TYMS presents a novel biomarker for diagnosis and prognosis in patients with pancreatic cancer. Medicine (Baltimore). 2019;98:e18487. doi: 10.1097/MD.000000000001 8487.

13. Bai W, Wu Y, Zhang P, Xi Y. Correlations between expression levels of thymidylate synthase, thymidine phosphorylase and dihydropyrimidine dehydrogenase, and efficacy of 5-fluorouracilbased chemotherapy for advanced colorectal cancer. Int J Clin Exp Pathol 2015;201;8:12333-45.

14. Chu E, Callender MA, Farrell MP, Schmitz JC. Thymidylate synthase inhibitors as anticancer agents: from bench to bedside. Cancer Chemother Pharmacol 2003;52 Suppl 1:S80-9. doi: 10.1007/s00280-003-0625-9..

15. Pellicer M, García-González X, García MI, et al. Identification of new SNPs associated with severe toxicity to capecitabine. Pharmacol Res 2017;120:133-7. doi: 10.1016/j.phrs.2017.03.021

16. Miller AB, Hoogstraten B, Staquet M, Winkler A. Reporting results of cancer treatment. Cancer 1981;47:207-14. doi: 10.1002/1097-0142 (19810 101)47:1<207::aid-cncr2820470134>3 .0.co;2-6.

Submissions: March 19, 2020

Revision received: May 13, 2020

Accepted for publication: May 13, 2020 